\title{
Evidence for interaction between genetic liability and childhood trauma in the development of psychotic symptoms
}

\author{
Florentina M. E. Pinckaers ${ }^{1}$ - Iris L. M. Rotee ${ }^{1}$. C. Vicky Nwosu ${ }^{1}$ - Pauline Krolinski ${ }^{1}$. Antonius P. W. Smeets ${ }^{1}$. \\ Sinan Gülöksüz ${ }^{2,3}$ • Lea de Jong ${ }^{1}$ · Thomas S. J. Vaessen ${ }^{1}$. Thomas Damen ${ }^{1}$ • Aniek Uittenboogaard ${ }^{1}$. \\ Annika T. Schäfer ${ }^{1} \cdot$ Claudia Menne-Lothmann $^{2} \cdot$ Jeroen Decoster ${ }^{2,4,5} \cdot$ Ruud van Winkel $^{2,4,5} \cdot$ Dina Collip ${ }^{2}$. \\ Philippe Delespaul $^{2,6} \cdot$ Marc De Hert $^{4,5} \cdot$ Catherine Derom $^{7,8} \cdot$ Evert Thiery $^{9} \cdot$ Nele Jacobs $^{2,10} \cdot$ Marieke Wichers $^{2,11}$. \\ Bart P. F. Rutten ${ }^{2} \cdot \operatorname{Jim}$ van $0 s^{2,12,13} \cdot$ Marjan Drukker $^{2} \mathbb{0}$
}

Received: 6 July 2018 / Accepted: 8 April 2019 / Published online: 17 June 2019

(c) The Author(s) 2019

\begin{abstract}
Purpose Whilst childhood trauma (CT) is a known risk factor across the spectrum of psychosis expression, little is known about possible interplay with genetic liability.

Methods The TwinssCan Study collected data in general population twins, focussing on expression of psychosis at the level of subthreshold psychotic experiences. A multilevel mixed-effects linear regression analysis was performed including 745 subjects to assess the interaction between genetic liability and CT. The Symptom Checklist-90 (SCL-90-R) score of the cotwin was used as an indirect measure of genetic liability to psychopathology, while the Childhood Trauma Questionnaire Short-Form (CTQ-SF) was used to assess CT in the domains of physical, emotional and sexual abuse, as well as physical and emotional neglect. The Community Assessment of Psychic Experience (CAPE) questionnaire was used to phenotypically characterize psychosis expression.

Results In the model using the CAPE total score, the interaction between CT and genetic liability was close to statistical significance $\left(\chi^{2}=5.6, d f=2, p=0.06\right)$. Analyses of CAPE subscales revealed a significant interaction between CT and genetic liability $\left(\chi^{2}=8.8, d f=2, p=0.012\right)$ for the CAPE-negative symptoms subscale, but not for the other two subscales (i.e. positive and depressive).

Conclusion The results suggest that the impact of CT on subthreshold expression of psychosis, particularly in the negative subdomain, may be larger in the co-presence of significant genetic liability for psychopathology.
\end{abstract}

Keywords Psychotic symptoms · Gene-environment interaction · Childhood trauma · General population · Genetic liability

Marjan Drukker

Marjan.Drukker@MaastrichtUniversity.nl

1 Faculty of Health Medicine and Life Sciences, Maastricht University, Maastricht, The Netherlands

2 Department of Psychiatry and Neuropsychology, School for Mental Health and Neuroscience (MHeNS), European Graduate School of Neuroscience (EURON), Maastricht University Medical Centre, Maastricht, The Netherlands

3 Department of Psychiatry, Yale School of Medicine, New Haven, CT, USA

4 University Psychiatric Centre, Catholic University Leuven, Leuven, Belgium

5 Department of Neurosciences, KU Leuven - University Psychiatric Centre, Kortenberg, Belgium

6 Mondriaan Mental Health Trust, Heerlen, The Netherlands
7 Centre of Human Genetics, University Hospitals Leuven, KU Leuven, Leuven, Belgium

8 Department of Obstetrics and Gynaecology, Ghent University Hospitals, Ghent University, Ghent, Belgium

9 Department of Neurology, Ghent University Hospital, Ghent University, Ghent, Belgium

10 Faculty of Psychology and Educational Sciences, Open University of the Netherlands, Heerlen, The Netherlands

11 Department of Psychiatry, Interdisciplinary Center Psychopathology and Emotion Regulation (ICPE), University of Groningen, University Medical Center Groningen, Groningen, The Netherlands

12 King's Health Partners Department of Psychosis Studies, Institute of Psychiatry, King's College London, London, UK

13 Department of Psychiatry, Brain Centre Rudolf Magnus, University Medical Centre Utrecht, Utrecht, The Netherlands 


\section{Introduction}

Studying risk factors for schizophrenia can be important because of the high burden of this illness. However, there is interplay between genetic liability and environment, making the search for risk factors more complicated.

Psychotic syndromes present on a spectrum of severity ranging from subthreshold 'schizotypy' states, characterised by subclinical psychotic experiences in the general population at one end of the spectrum, to the diagnosis of schizophrenia indicating relatively poor outcome at the other end [1]. Studying psychosis expression in the general population, below the threshold of clinical need, may shed light on mechanisms that drive expression across the spectrum and now represents a widely used paradigm [2]. The spectrum of psychotic syndromes shows a variation in both the severity of symptoms and a variation in symptompatterns experienced by individuals [3]. It is important to acknowledge the multidimensional expression of the psychotic syndrome, especially with respect to subclinical psychotic experiences. In the general population subclinical psychotic experiences may refer to isolated psychotic symptoms, in specific domains, that are not severe enough for a psychiatric diagnosis, but are associated with increased risk for suicidal behaviour, nonpsychotic psychiatric disorders and functional disability [4]. For this reason, dimensions of psychosis in the general population can be seen as different outcomes that need to be studied separately.

Epidemiological research has identified various environmental risk factors for psychotic disorder and expression across the spectrum of severity, opening up the possibility to examine gene-environment interplay using direct and indirect measures of genetic risk [5, 6]. Meta-analytic work suggests that childhood trauma (CT) is an important environmental risk factor for psychotic disorder [7]. A study in children aged 12 years reported that CT was associated with psychotic symptoms regardless of whether these events occurred early in life or later in childhood [8]. $\mathrm{CT}$ is a broad concept, which includes a number of severe and adverse experiences from either a sexual, physical or emotional origin. In the present paper, CT is defined as physical abuse, physical neglect, emotional abuse, emotional neglect and sexual abuse. Other domains of childhood adversity such as bullying, domestic violence, parental death were not included. As the genetic component of schizophrenia risk [9] as well as its overlap with genetic liability for affective and other syndromes [10-12] are well established, interplay between $\mathrm{CT}$ and genetic risk can be examined.

The increased vulnerability of subjects at high-risk for psychosis can be related to environmental risk factors such as CT, as demonstrated by a recent meta-analysis [13].
However, the role of genetic and epigenetic risk factors in this association remains to be further clarified [14]. Several studies have explored the interaction between specific genes and $\mathrm{CT}$ in the development of psychosis, but lack information on overall genetic risk [5, 15-17]. In this regard, the polygenic risk score provides a promising variable, since the entire scope of genome-wide association can be turned into a simple measure [18]. To this date, only Trotta and colleagues have explored whether a polygenic risk score modifies the association between $\mathrm{CT}$ and psychosis [19]. As a result of an underpowered sample, their study was not able to detect the likely genetic and environmental interactions in psychosis [19]. The present study also uses a measure of overall genetic liability as opposed to studies assessing specific genes [5, 16, 17], but does not use GWAS results. The twin design represents a useful way to study gene-environment interplay, as the level of psychopathology in one twin can be used as a marker of genetic risk for psychopathology in the other, depending on the degree of shared genes $(100 \%$ for monozygotic [MZ] twins and 50\% for dizygotic [DZ] twins).

The aim of the present study is to examine whether the level of psychotic experiences in twins is increased as a function of the interaction between environmental risk (CT) and genetic liability. Since the expression of the psychotic syndrome is multidimensional [20], three dimensions were analysed separately: positive symptoms, negative symptoms and depressive symptoms.

\section{Methods}

\section{Sample and response}

Participants were recruited from the East Flanders Prospective Twin Survey (EFPTS [21]), a prospective populationbased, multi-birth registry situated in Flanders, Belgium. Zygosity was determined through sequential analysis based on sex, fetal membranes, umbilical cord blood groups, placental alkaline phosphatase, and DNA fingerprints. The TwinssCan project collected data on adolescents and young adults from the EFPTS [22]. The study population is aged between 15 and 35 years and includes twins, their siblings, and parents. Participants were included if they understood the study procedure, were able to provide valid, reliable, and complete data, that is from all twins in the twin pair or triplet.

988 twin pairs who were registered in the EFPTS, fulfilled the inclusion criteria and who earlier indicated that they would not mind to participate in scientific research were invited to participate in the TwinssCan project. 297 twin pairs responded (30\%). In addition, an announcement was 
made in the newsletter that is sent to all twins in the EFPTS to recruit more participants. This resulted in an extra 96 twin pairs. Since there were 6 triplets the total number of participants is 792 .

All participants gave written informed consent; for participants below the age of 18, parents also signed an informed consent. Participants were excluded if they had a pervasive mental disorder as indicated by caregivers. The local ethics committee (Commissie Medische Ethiek van de Universitaire ziekenhuizen KU Leuven, Nr. B32220107766) approved the study. For the present analysis, siblings and parents were excluded.

\section{Instruments}

The Community Assessment of Psychic Experience (CAPE) is a self-report instrument including items on lifetime psychotic experiences (positive, negative, depressive) [23]. Mark and Toulopoulou [4] confirmed the factorial validity of CAPE's 3-dimensional structure and the subscale structures to facilitate for diverse research objectives in clinical use. For the present paper, the 42 -item version was used. It has a high internal stability for detecting subthreshold experiences and adequate reliability and validity [23]. The CAPE measures both frequency and distress. For the present paper, only the frequency items were used. Those were measured on a four-point Likert scale; never (1), sometimes (2), often (3), nearly always (4). The CAPE overall sum score as well as the subscales of positive, negative, and depressive symptoms were outcomes in the present study. Measures of hypomania and disorganization are not included in the CAPE, given the complexity of capturing these by self-report in the general population.

The Childhood Trauma Questionnaire Short-Form (CTQ$\mathrm{SF}$ ) is a retrospective 28-item self-report questionnaire used to assess the extent to which the respondents experienced five types of negative childhood experiences: physical, sexual, and emotional abuse, and physical and emotional neglect [24]. If necessary, item scores were reversed. Three items assessed the validity of the questionnaire; these were excluded from the sum score. Each clinical subscale includes five items, and severity scores for each subscale can range between 5 and 25 [17, 24].

Due to the fact that the association between CTQ-SF and CAPE was non-linear, sum scores of the CTQ-SF were categorised. All subjects scoring above the cutoff point for moderate or severe CT as defined by Bernstein, Fink [17] (physical abuse 10, physical neglect 10, emotional abuse 13, emotional neglect 15 , sexual abuse 8 ), were defined as CT in a dichotomous variable.

The Symptom Checklist-90-Revised (SCL-90-R) is a frequently used instrument including 90 items to screen psychopathology $[25,26]$ and it is available in the Dutch language [27]. Reliability and validity of the SCL-90-R have been established previously $[26,28]$. SCL-90-R total sum scores at baseline and at first follow-up (after 1 year) were averaged to obtain co-twin psychopathology scores (see below).

Genetic liability was defined on the basis of (i) the level of psychopathology of the co-twin as assessed with the SCL90-R [29] and (ii) the level of shared genes in the co-twin, consistent with previous papers [30-32]. The correlation in psychopathology score between MZ and DZ twins is the result of genetics or noise, assuming the degree of sharing an exposure to environmental risk factors is similar for $\mathrm{MZ}$ and DZ twins [31]. Co-twins scoring in the lowest three quartiles of the SCL-90-R total score were defined as having a low level of psychopathology and those scoring in the highest quartile as having a high level of psychopathology. Three categories of genetic liability were thus generated: (1) the co-twin has a low psychopathology score (MZ DZ low); (2) the dizygotic co-twin has a high psychopathology score (DZ high); (3) the monozygotic co-twin has a high psychopathology score (MZ high).

\section{Statistical analyses}

All analyses were performed using Stata 13 [33]. The data had a multilevel structure with individuals being clustered within twin pairs. Therefore, multilevel mixed-effects linear regression analyses were performed. The dependent variables were the CAPE total score and the positive, negative, and depressive subscales of the CAPE. The main independent variables were $\mathrm{CT}$ and genetic liability. In addition, the interaction $\mathrm{CT} *$ genetic liability was added to all models. Since linear regression was performed, interaction was analysed on an additive scale [34]. Age and gender were included as confounders. When the $p$ value of the interaction $\mathrm{CT} *$ genetic liability was below 0.1 , the Stata lincom routine was used to obtain regression coefficients of CT across the different categories of genetic liability.

\section{Results}

For the present analysis, data pertaining to 745 twins without missing data were used (genetic liability was missing in 37 twins). The present sample included both males and females, and both dizygotic and monozygotic twins. Sixty percent was female and the mean age was 17.2 years (Tables 1,2 ). Ethnicity in the sample was rather homogeneous $(96.2 \%$ speaks the Flemish language). A total of 138 subjects (18.5\%) had at least one type of CT (Table 3). This was similar to or lower than other general population samples (Brazil $17 \%$ [35]; China, no total, subscales 11, 7, 2, 2, 5, respectively [36]) and far lower than various patient groups and a 
Table 1 Descriptive statistics: dichotomous variables

\begin{tabular}{ll}
\hline & $N(\%)$ \\
\hline $\begin{array}{l}\text { Number of study subjects } \\
\text { Genetic psychopathology risk factor }\end{array}$ & 745 \\
MZ DZ low & \\
DZ high & $562(75.4 \%)$ \\
MZ high & $113(15.2 \%)$ \\
Gender & $70(9.4 \%)$ \\
Male & \\
Female & $299(40.1 \%)$ \\
Age categories & $446(59.9 \%)$ \\
14-15 year & \\
16-18 year & $329(44.2 \%)$ \\
19-34 year & $260(34.9 \%)$ \\
Number of twins & $156(20.9 \%)$ \\
MZ & \\
DZ & $269(36.1 \%)$ \\
\hline
\end{tabular}

${ }^{a}$ Dizygotic high risk (DZ high), monozygotic high risk (MZ high); monozygotic and dizygotic low risk (MZ DZ low)

Table 2 Descriptive statistics: continuous variables

\begin{tabular}{lllrl}
\hline Variables & $N$ & Mean & SD & Range \\
\hline Overall sum score CTQ-SF $^{\mathrm{a}}$ & 745 & 34.0 & 8.0 & $25-82$ \\
Age & 745 & 17.2 & 3.3 & $14-34$ \\
Overall sum score CAPE & 745 & 65.9 & 10.9 & $44-127$ \\
Subscale-positive CAPE & 745 & 28.3 & 5.5 & $20-62$ \\
Subscale-negative CAPE & 745 & 23.5 & 4.8 & $14-46$ \\
Subscale depression CAPE & 745 & 14.1 & 2.9 & $8-29$ \\
\hline
\end{tabular}

${ }^{\mathrm{a}}$ Childhood Trauma Questionnaire Short-Form (CTQ-SF); Community Assessment of Psychotic Experience questionnaire (CAPE)

Table 3 Distribution of types of childhood trauma (CT) determined by scores on the Childhood Trauma Questionnaire Short-Form (CTQ-SF) in our study population consisting of 745 twins from the general population

\begin{tabular}{lrr}
\hline & \multicolumn{2}{c}{ N } \\
\hline Physical abuse & 10 & 1.3 \\
Physical neglect & 68 & 9.1 \\
Emotional abuse & 69 & 9.3 \\
Emotional neglect & 41 & 5.5 \\
Sexual abuse & 22 & 2.9 \\
Total & 138 & 18.5 \\
\hline
\end{tabular}

homeless control sample [36-38]. CT and genetic liability were associated $\left(\chi^{2}=8.2, d f=2, p=0.016\right)$. The proportion of subjects exposed to CT differed with a maximum of $10 \%$ between the strata of genetic liability $(16 \%, 26 \%$ and $26 \%$ in MZ DZ low, DZ high and MZ high, respectively).

In the regression model of the CAPE total score, the interaction between CTQ-SF and genetic liability was close to statistical significance $\left(\chi^{2}=5.6, d f=2, p=0.06\right.$, table 4$)$. The
CAPE subscale for negative symptoms showed a significant interaction with genetic liability $\left(\chi^{2}=8.8, d f=2, p=0.012\right.$, Table 4). Thus, the association between $\mathrm{CT}$ and negative symptoms was significantly higher in the MZ high group than both the low group and the DZ high group (Fig. 1). Although the interaction was not statistically significant, the Stata lincom routine showed a similar pattern in the total CAPE (Fig. 1). No significant interaction between CT and genetic liability was found for the CAPE-positive or depressive symptoms subscales (Table 4). The regression coefficients of the associations between $\mathrm{CT}$ and positive symptoms and between $\mathrm{CT}$ and depressive symptoms were $3.1(p<0.001)$ and $1.7(p<0.001)$, respectively (Table 4$)$.

\section{Discussion}

The interaction between CT and genetic liability in the association with psychotic symptoms, measured with the CAPE, was close to statistical significance. This was driven by a significant interaction between CT and genetic liability in the model of the CAPE-negative symptoms subscale. This tentatively suggests that there is an interaction between CTQ-SF and genetic liability.

Despite the large differences when analysing the CAPE total score, regression coefficients of 5.8, 4.7 and 12.4 were not significantly different from each other. In general, a large sample size is required to show interaction [39-41]. With 745 twins, the study is not small, but power to show interaction effects nevertheless remains relatively low. The low numbers in the MZ high group $(n=70 ; 9.4 \%)$ and the low prevalence of CT $(n=138 ; 18.5 \%)$ further reduced power. Despite this, results did show statistically significant interaction in CAPE-negative symptoms. With more power, interaction in CAPE total analyses might also have been statistically significant.

There are various types of constructs to study genetic liability when aiming to study an omnibus measure, rather than molecular measures. Two studies using family history and sibling status (sibling of patient with non-affective psychotic disorder) as an omnibus measure for genetic liability showed gene-environment interaction [42, 43]. More specifically, associations between various environmental factors and the continuum of psychosis were stronger on an additive scale in subjects with a family history of psychiatric disorder [42]. Two adoptive studies assessing adoptive parents' communication deviance and biological mothers' diagnosis of schizophrenia spectrum disorder and schizophrenia, respectively, also showed gene-environment interaction [44, 45]. On the other hand, two other studies using family history to assess genetic liability did not show interaction between CT and parental psychopathology [46, 47]. A study in young adolescents defined genetic liability using information on 
Table 4 Interaction between genetic liability determined by the SCL-90 score of the co-twin and childhood trauma determined by scores on the Childhood Trauma Questionnaire Short-Form (CTQ-SF) using the CAPE score as outcome

\begin{tabular}{|c|c|c|c|c|}
\hline CAPE sum score $\rightarrow$ & Overall & Positive & Negative & Depressive \\
\hline Chi-square of interaction term & $\begin{array}{c}\chi^{2}=5.6 d f=2 \\
p=0.06\end{array}$ & $\chi^{2}=1.7 d f=2 p=0.43$ & $\begin{array}{c}\chi^{2}=8.79 d f=2 \\
p=0.012\end{array}$ & $\chi^{2}=1.36 d f=2 p=0.51$ \\
\hline Regression coefficient of CT & See Fig. 1 & $B=3.1 p<0.001$ & See Fig. 1 & $B=1.7 p<0.001$ \\
\hline
\end{tabular}

(A)

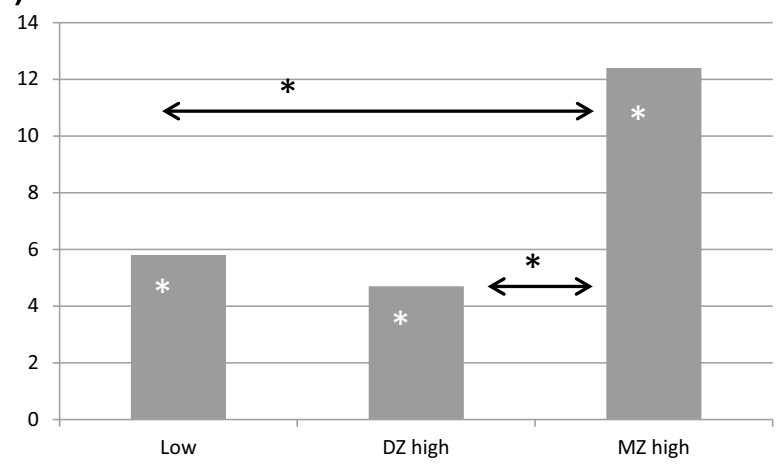

(B)

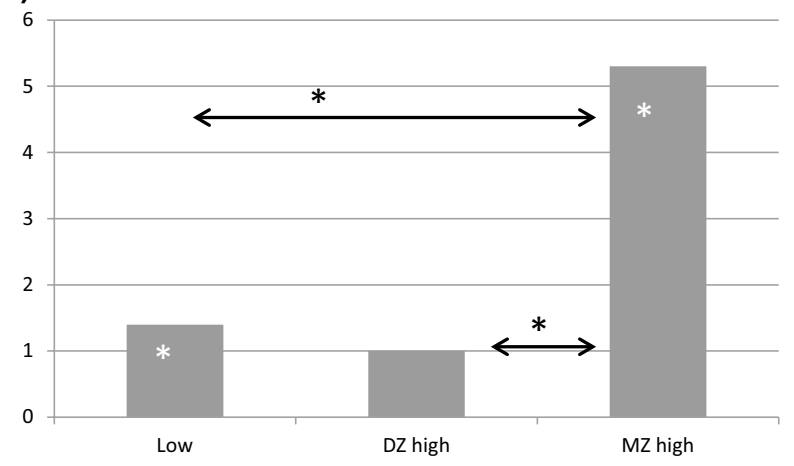

Fig. 1 Regression coefficients representing the association between childhood trauma and the Community Assessment of Psychic Experience (CAPE) scores in twins with a low genetic risk (DZ-MZ Low) or a dizygotic (DZ) or monozygotic (MZ) high risk, respectively. a overall sum score, b sub scale negative symptoms ${ }^{\mathrm{a}}$. ${ }^{\mathrm{a}}$ Regression coefficients show the increase in CAPE score for subjects with CT compared to subjects without CT. $* p<0.05$

psychosis from the co-twin [8]. This study did not show interaction between $\mathrm{CT}$ and a genetic liability variable constructed using information on psychosis from the co-twin [8]. A difference with the present study, however, is that this study used psychotic symptoms in the co-twin rather than general psychopathology in the co-twin. The difference in age range (12 years vs $14-34$ years) can also be responsible for the differences in findings. Thus, while from the present results we only tentatively concluded that there is evidence for interaction, previous results from studies using omnibus measures are also not consistent and more research is needed.
The aetiology of schizophrenia heritability is polygenic [48]. More than 150 schizophrenia-associated loci have been identified using genome-wide association studies (GWAS) [9]. The polygenic risk score includes the full spectrum of genetic liability [49] and is also ideally suited to study gene-environment interaction. A pilot case-control study did not find evidence for the interaction between polygenic risk score and CT, but power was relatively low for the study of interaction. The biological significance of the polygenic risk score remains uncertain. Specific polygenic pathway scores may be more biologically informative, but a priori hypotheses justifying the use of any specific pathway are not precise and false-positive findings may ensue. Given the current weak evidence future research studying the polygenic risk score can shed more light on the gene-environment interaction [18]. Given the difficulties in using molecular measures of genetic risk, additional studies using indirect measures of genetic risk also remain useful.

\section{GxE in CAPE-negative symptoms}

The present results showed an interaction between $\mathrm{CT}$ and genetic liability in CAPE-negative symptoms but not in CAPE-positive or depressive symptoms. Previous research showed the main effects of CT were larger when analysing positive symptoms $[14,50]$. Despite the need to analyse CAPE scales separately [4], the above-mentioned studies showing interaction did not differentiate between positive and negative symptoms [42-45]. It has been suggested that childhood neglect specifically interferes with the development of negative symptoms and that poor attachment is on the causal pathway [51]. The traumagenetic neurodevelopmental theory proposes that neurological and biochemical abnormalities found in adult schizophrenia are caused by child abuse because long-lasting biological effects accumulate over time [52]. In this theory, the two interacting patterns of response to $\mathrm{CT}$ are hyperarousal and the biological stress system. By reacting through hypervigilance, a phenomenon called pruning may be emphasized. This is a normal reaction which occurs in adolescence and corresponds to a decrease in the number of synapses and neuronal loss mainly in the neuropil. However, when accentuated, there is excessive neuronal loss which might be the root of progression towards negative symptoms in adulthood [53, 54]. Further research is required to examine this issue. 


\section{Intra class correlation and differences between CT subscales}

It is plausible that the environment is more similar in $\mathrm{MZ}$ twins than in DZ twins and this would make the equal exposure assumption invalid [55]. Subsequently, this would mean that genetic liability as used in the present paper may be confounded by the environment because the exposure is, similar to genes, also shared to a greater degree in MZ twins. When examining the intra class correlation (ICC) of the CT subscales in MZ and DZ twins, physical abuse and physical neglect were more similar in MZ as compared to DZ twins, while there were no differences in the other subscales or in the total score (results available upon request). Results for the total CT and for emotional abuse were as expected; a large regression coefficient for the association between $\mathrm{CT}$ and CAPE score in MZ high, and not in DZ high or in MZ DZ low. On the contrary, in the subscales with differences in ICC, DZ high showed the highest degree of interaction, with directionally the lowest or even negative regression coefficients (reversed interaction). Given the differences in ICC in the subscales of physical abuse and physical neglect, we suggest that only the results for CT total score and the other subscales are valid. This also means that we implicitly assumed that all CT subscales included in the present paper show the same interaction with genetic liability. In previous studies, this assumption was also made [42, 43, 47] or only one domain was studied [46]. Because the present results only show differences between physical abuse and neglect on the one hand and emotional abuse and neglect on the other and this seems related to differences in intraclass correlation (see above), intention to harm in the abuse variables does not seem to make a difference. This contradicts previous findings [8]. Future studies in populations with higher CT prevalences can further assess interaction between genetic liability and the subscales.

\section{Gene-environment correlation}

In the present data, genetic liability and CT were associated. It has been argued that the presence of gene-environment correlation hampers the interpretation of gene-environment interaction results because in the event of correlation, CT can be on the causal pathway between genetic liability and the outcome [56-58]. Linear regression analysis, as used in the present paper, is ideally suited to disentangle association from interaction. In addition, because of the relatively low correlation, we expected, if any, partial rather than full mediation. To show that the present findings are not the result of mediation, we tested mediation in a model without interaction. The uncorrected regression coefficient between MZ high risk and CAPE total score was 2.4 ( $p=0.08$, reference MZ DZ low). After including CT, the regression coefficient increased to $3.2(p=0.017)$; when assessing CAPE negative symptoms, the regression coefficient was 1.09 (n.s.) in a crude model and 1.13 (n.s.) after including the CT. Therefore, in the present study, the presence of apparent gene-environment correlation could not be interpreted as evidence of mediation. In addition, an analysis using an MZ twin approach in the TwinssCan data showed an association between $\mathrm{CT}$ and psychosis that cannot result from gene-environment correlation [58].

\section{Methodological issues}

CAPE is not useful as a screening tool for psychotic disorders, since the prevalence of self-reported experiences is much higher than the prevalence of the clinical disorder according to the DSM-IV [23, 59]. In this setting, however, used as a screening tool for the prevalence for psychotic experiences as a broad measure of psychometric risk for psychosis, it is suitable.

The SCL-90-R was used to define genetic liability in the co-twin, while the different CAPE dimensions were the outcome in the regression models. Cross-trait within-twin analysis is a valid method to establish genetic liability [30]. SCL-90-R was suitable to define genetic liability because it assesses general psychopathology and elsewhere, we have shown that psychotic experiences in fact reflect severity of general psychopathology $[2,60,61]$ and that gene-environment interactions analyses can be productively studied using broad measures of psychopathology in defining proxy genetic risk [42, 62]. Thus, the measure of genetic liability for the different CAPE dimensions arguably should reflect the general psychopathology severity measure. The Pearson correlation between the dichotomous SCL-90-R (in the index twin) and the CAPE total score and subscales was between 0.41 and 0.54 , showing sufficient differentiation between the two scales for use as, respectively, genetic exposure and outcome measures.

There is no consensus on how to categorize the CTQSF. Frissen and colleagues [63] and Van Nierop and colleagues [43], therefore, used a cutoff at $80 \%$ to define CT based on the CTQ-SF. Other studies, used the tertiles cutoff to define groups [64]. In a general population sample, this might be invalid as the relatively low incidence of CT will result in subjects with low trauma ending up in the highest risk category. Therefore, we used the cutoffs as defined by Bernstein, Fink [17]. A sensitivity analysis of CTQ-SF categorised in tertiles showed very similar results. However, the $p$ value for the interaction term (CT* genetic liability) increased from 0.06 to 0.19 and from 0.012 to 0.15 in the model of total CAPE and CAPE-negative symptoms, respectively. In addition, although the CTQ-SF used in the present paper covers important constructs within the CT umbrella term, it does not cover the entire range. The CTQ-SF does 
not assess domains such as bullying, domestic violence and parental death, which have also been associated with psychosis outcomes $[8,65]$. Finally, although timing, severity and duration of CT are likely to impact later mental health outcomes $[8,65,66]$, these were not included in the present analyses. In the present sample, prevalence of CT was rather low, resulting in analyses of the dichotomised CTQ subscales. Future research analysing samples with higher CT prevalence should consider these aspects and include the full range of experiences associated with $\mathrm{CT}$.

One disadvantage of the solely retrospective use of the CTQ-SF is the fact that recall bias may occur. It is possible that a prospective tool would have shown CT in individuals currently classified as not having experienced CT. A previous validation study did show an association between CT and psychopathology regardless of whether a prospective or retrospective measurement tool was used, but retrospective self-reports often demonstrated stronger associations with psychopathology [67]. Possible explanations for this phenomenon include the underreporting of severe CT by caregivers in prospective tools and an increased 'knowledgeability' of patients about experienced CT in comparison to their parents [67]. 'Memory bias'-the improved recall of negative childhood experiences in an individual with current psychopathology — has been shown to only have a minimal influence on the correlation between self-reported CT and psychopathology [68]. Nevertheless, the current results cannot be extended to samples with prospective measures of CT.

In theory, the probability of recall bias may be highest in the oldest age group. Sensitivity analyses showed that in the youngest age groups the interaction term and regression coefficients in the genetic liability strata were similar to the main results. In the age categories with lowest recall bias, the interaction was strongest. This suggests that the stronger association in MZ high is not the result of recall bias.

Subjects included in the analyses differed from subjects with missing data (lower age and fewer with CT exposure). In addition, non-responder data were not available. Reasons for non-response were "research staff could not reach the subject", "refused", "not interested", "moved". Since only full twin pairs were included, non-response in one twin made the other twin not eligible. Previous research using the EFPTS showed that non-responders were similar in gender, mode of fertilisation, gestational age, parental age and behaviour; $\mathrm{MZ}$ were slightly overrepresented and birth weight was slightly higher [69]. There is no reason to expect differential non-response impacting associations and interactions assessed in the present paper (e.g. non-responders having both more genetic liability and lower CAPE scores than responders).

Furthermore, the analysis performed was restricted to data from the general population; no psychiatric patients were included. However, studying psychotic symptoms in the general population can contribute to unravelling the mechanism in full-blown clinical disorder [70]. We, therefore, believe that these results may be generalized to the clinical level, although this requires further study. Despite its exploratory nature, this study offers some insight into the interaction between genetic liability and CT. Nonetheless, more research on this topic needs to be undertaken to be able to draw definitive conclusions.

Acknowledgements Participants were recruited from the East Flanders Prospective Twin Survey (EFPTS) which is partly supported by the Association for Scientific Research in Multiple Births. Furthermore, the TwinssCan project is part of the European Community's Seventh Framework Program under grant agreement No. HEALTHF2-2009-241909 (Project EU-GEI).

\section{Compliance with ethical standards}

Conflict of interest The authors declare that they have no conflict of interest.

Ethics approval The local ethics committee (Commissie Medische Ethiek van de Universitaire ziekenhuizen KU Leuven, $\mathrm{Nr}$. B32220107766) approved the study.

Open Access This article is distributed under the terms of the Creative Commons Attribution 4.0 International License (http://creativeco mmons.org/licenses/by/4.0/), which permits unrestricted use, distribution, and reproduction in any medium, provided you give appropriate credit to the original author(s) and the source, provide a link to the Creative Commons license, and indicate if changes were made.

\section{References}

1. Linscott RJ, van Os J (2013) An updated and conservative systematic review and meta-analysis of epidemiological evidence on psychotic experiences in children and adults: on the pathway from proneness to persistence to dimensional expression across mental disorders. Psychol Med 43(6):1133-1149. https://doi.org/10.1017/ S0033291712001626

2. van Os J, Reininghaus U (2016) Psychosis as a transdiagnostic and extended phenotype in the general population. World Psychiatry 15(2):118-124. https://doi.org/10.1002/wps.20310

3. Wigman JTW, Wardenaar KJ, Wanders RBK, Booij SH, Jeronimus BF, van der Krieke L et al (2017) Dimensional and discrete variations on the psychosis continuum in a Dutch crowd-sourcing population sample. Eur Psychiatry 42:55-62. https://doi. org/10.1016/j.eurpsy.2016.11.014

4. Mark W, Toulopoulou T (2016) Psychometric properties of "community assessment of psychic experiences": review and metaanalyses. Schizophr Bull 42(1):34-44. https://doi.org/10.1093/ schbul/sbv088

5. Caspi A, Moffitt TE (2006) Gene-environment interactions in psychiatry: joining forces with neuroscience. Nat Rev Neurosci 7(7):583-590. https://doi.org/10.1038/nrn1925

6. van Os J, Kenis G, Rutten BP (2010) The environment and schizophrenia. Nature 468(7321):203-212. https://doi.org/10.1038/natur e09563

7. Varese F, Smeets F, Drukker M, Lieverse R, Lataster T, Viechtbauer W et al (2012) Childhood adversities increase the risk of 
psychosis: a meta-analysis of patient-control, prospective- and cross-sectional cohort studies. Schizophr Bull 38(4):661-671. https://doi.org/10.1093/schbul/sbs050

8. Arseneault L, Cannon M, Fisher HL, Polanczyk G, Moffitt TE, Caspi A (2011) Childhood trauma and children's emerging psychotic symptoms: a genetically sensitive longitudinal cohort study. Am J Psychiatry 168(1):65-72. https://doi.org/10.1176/ appi.ajp.2010.10040567

9. Schizophrenia Working Group of the Psychiatric Genomics Consortium (2014) Biological insights from 108 schizophreniaassociated genetic loci. Nature 511(7510):421-427. https://doi. org/10.1038/nature 13595

10. Cardno AG, Marshall EJ, Coid B, Macdonald AM, Ribchester TR, Davies NJ et al (1999) Heritability estimates for psychotic disorders: the Maudsley twin psychosis series. Arch Gen Psychiatry $56(2): 162-168$

11. Cross-Disorder Group of the Psychiatric Genomics C, Lee SH, Ripke S, Neale BM, Faraone SV, Purcell SM et al. (2013) Genetic relationship between five psychiatric disorders estimated from genome-wide SNPs. Nat Genet 45 (9):984-994. doi: $10.1038 /$ ng. 2711

12. van Os J, van der Steen Y, Islam MA, Guloksuz S, Rutten BP, Simons CJ et al (2017) Evidence that polygenic risk for psychotic disorder is expressed in the domain of neurodevelopment, emotion regulation and attribution of salience. Psychol Med 47(14):2421-2437. https://doi.org/10.1017/S00332917170009 15

13. Fusar-Poli P, Tantardini M, De Simone S, Ramella-Cravaro V, Oliver D, Kingdon J et al (2017) Deconstructing vulnerability for psychosis: Meta-analysis of environmental risk factors for psychosis in subjects at ultra high-risk. Eur Psychiatry 40:65-75. https:// doi.org/10.1016/j.eurpsy.2016.09.003

14. Alemany S, Arias B, Aguilera M, Villa H, Moya J, Ibanez MI et al (2011) Childhood abuse, the BDNF-Val66Met polymorphism and adult psychotic-like experiences. Br J Psychiatry 199(1):38-42. https://doi.org/10.1192/bjp.bp.110.083808

15. Ramsay H, Kelleher I, Flannery P, Clarke MC, Lynch F, Harley $M$ et al (2013) Relationship between the COMT-Val158Met and BDNF-Val66Met polymorphisms, childhood trauma and psychotic experiences in an adolescent general population sample. PLoS One 8(11):e79741. https://doi.org/10.1371/journal.pone.0079741

16. van Winkel R, Stefanis NC, Myin-Germeys I (2008) Psychosocial stress and psychosis. A review of the neurobiological mechanisms and the evidence for gene-stress interaction. Schizophr Bull 34 (6):1095-1105. doi:10.1093/schbul/sbn101

17. Bernstein DP, Fink L (1998) Childhood trauma questionnaire: a retrospective self-report manual. Psychological Corporation, San Antonio, TX

18. Iyegbe C, Campbell D, Butler A, Ajnakina O, Sham P (2014) The emerging molecular architecture of schizophrenia, polygenic risk scores and the clinical implications for GxE research. Soc Psychiatry Psychiatr Epidemiol 49(2):169-182. https://doi.org/10.1007/ s00127-014-0823-2

19. Trotta A, Iyegbe C, Di Forti M, Sham PC, Campbell DD, Cherny SS et al (2016) Interplay between schizophrenia polygenic risk score and childhood adversity in first-presentation psychotic disorder: a pilot study. PLoS One 11(9):e0163319. https://doi. org/10.1371/journal.pone.0163319

20. Stefanis NC, Hanssen M, Smirnis NK, Avramopoulos DA, Evdokimidis IK, Stefanis CN et al (2002) Evidence that three dimensions of psychosis have a distribution in the general population. Psychol Med 32(2):347-358

21. Derom C, Thiery E, Peeters H, Vlietinck R, Defoort P, Frijns JP (2013) The East Flanders Prospective Twin Survey (EFPTS): an actual perception. Twin Res Hum Genet 16(1):58-63. https://doi. org/10.1017/thg.2012.75
22. Pries LK, Guloksuz S, Menne-Lothmann C, Decoster J, van Winkel R, Collip D et al (2017) White noise speech illusion and psychosis expression: an experimental investigation of psychosis liability. PLoS One 12(8):e0183695. https://doi.org/10.1371/journ al.pone. 0183695

23. Konings M, Bak M, Hanssen M, van Os J, Krabbendam L (2006) Validity and reliability of the CAPE: a self-report instrument for the measurement of psychotic experiences in the general population. Acta Psychiatr Scand 114(1):55-61. https://doi.org/10.111 1/j.1600-0447.2005.00741.x

24. Scher CD, Stein MB, Asmundson GJ, McCreary DR, Forde DR (2001) The childhood trauma questionnaire in a community sample: psychometric properties and normative data. J Trauma Stress 14(4):843-857. https://doi.org/10.1023/A:1013058625719

25. Derogatis LR (1977) SCL-90: administration, scoring and procedures manual-1 for the R(evisited) version. John Hopkins School of Medicine, Clinical Psychometrics Research Unit, Baltimore, MD

26. Derogatis LR, Cleary PA (1977) Factorial invariance across gender for the primary symptom dimensions of the SCL-90. Br J Soc Clin Psychol 16(4):347-356

27. Arrindell WA, Ettema JHM (2003) Symptom Checklist. Handleiding bij een multidimensionele psychopathologie-indicator, Lisse

28. Bonicatto S, Dew MA, Soria JJ, Seghezzo ME (1997) Validity and reliability of Symptom Checklist '90 (SCL90) in an Argentine population sample. Soc Psychiatry Psychiatr Epidemiol 32(6):332-338

29. Kendler KS, Diehl SR (1993) The genetics of schizophrenia: a current, genetic-epidemiologic perspective. Schizophr Bull 19(2):261-285

30. Lataster T, Myin-Germeys I, Derom C, Thiery E, van Os J (2009) Evidence that self-reported psychotic experiences represent the transitory developmental expression of genetic liability to psychosis in the general population. Am J Med Genet B Neuropsychiatr Genet 150B(8):1078-1084. https://doi.org/10.1002/ajmg.b.30933

31. Wichers M, Myin-Germeys I, Jacobs N, Peeters F, Kenis G, Derom C et al (2007) Genetic risk of depression and stressinduced negative affect in daily life. Br J Psychiatry 191:218-223. https://doi.org/10.1192/bjp.bp.106.032201

32. Wichers M, Schrijvers D, Geschwind N, Jacobs N, Myin-Germeys I, Thiery E et al (2009) Mechanisms of gene-environment interactions in depression: evidence that genes potentiate multiple sources of adversity. Psychol Med 39(7):1077-1086. https://doi. org/10.1017/S0033291708004388

33. StataCorp (2013) Stata Statistical Software, 13th edn. Stata Corporation, College Station, TX

34. Darroch (1997) Biologic synergism and parallelism. Am J Epid 145(7):661-668

35. Jansen K, Cardoso TA, Fries GR, Branco JC, Silva RA, KauerSant'Anna M et al (2016) Childhood trauma, family history, and their association with mood disorders in early adulthood. Acta Psychiatr Scand 134(4):281-286. https://doi.org/10.1111/ acps. 12551

36. Xie P, Wu K, Zheng Y, Guo Y, Yang Y, He J et al (2018) Prevalence of childhood trauma and correlations between childhood trauma, suicidal ideation, and social support in patients with depression, bipolar disorder, and schizophrenia in southern China. J Affect Disord 228:41-48. https://doi.org/10.1016/j. jad.2017.11.011

37. Vangeel EB, Kempke S, Bakusic J, Godderis L, Luyten P, Van Heddegem L et al (2018) Glucocorticoid receptor DNA methylation and childhood trauma in chronic fatigue syndrome patients. J Psychosom Res 104:55-60. https://doi.org/10.1016/j.jpsychores .2017.11.011

38. Song MJ, Nikoo M, Choi F, Schutz CG, Jang K, Krausz RM (2018) Childhood Trauma and Lifetime Traumatic Brain Injury 
Among Individuals Who Are Homeless. J Head Trauma Rehabil 33(3):185-190. https://doi.org/10.1097/HTR.000000000000031 0

39. Pearce N (2018) A short introduction to epidemiology. Chapter 7\&8: Effect Modification. https://www.sld.cu/galerias/pdf/ sitios/vigilancia/asite2_chapter_7.pdf. Accessed 26 June 2018

40. Bellinger DC (2000) Effect modification in epidemiologic studies of low-level neurotoxicant exposures and health outcomes. Neurotoxicol Teratol 22(1):133-140

41. Leon AC, Heo M (2009) Sample sizes required to detect interactions between two binary fixed-effects in a mixed-effects linear regression model. Comput Stat Data Anal 53(3):603-608. https ://doi.org/10.1016/j.csda.2008.06.010

42. Radhakrishnan R, Guloksuz S, Ten Have M, de Graaf R, van Dorsselaer S, Gunther N et al. (2018) Interaction between environmental and familial affective risk impacts psychosis admixture in states of affective dysregulation. Psychol Med:1-11. doi:10.1017/S0033291718002635

43. van Nierop M, Janssens M, OoPI Genetic Risk, Bruggeman R, Cahn W, de Haan L et al (2013) Evidence that transition from health to psychotic disorder can be traced to semi-ubiquitous environmental effects operating against background genetic risk. PLoS One 8(11):e76690. https://doi.org/10.1371/journ al.pone. 0076690

44. Roisko R, Wahlberg KE, Hakko H, Tienari P (2015) Association of adoptive child's thought disorders and schizophrenia spectrum disorders with their genetic liability for schizophrenia spectrum disorders, season of birth and parental Communication Deviance. Psychiatry Res 226(2-3):434-440. https://doi.org/10.1016/j.psych res.2014.12.036

45. Wahlberg KE, Wynne LC, Oja H, Keskitalo P, Pykalainen L, Lahti I et al (1997) Gene-environment interaction in vulnerability to schizophrenia: findings from the Finnish Adoptive Family Study of Schizophrenia. Am J Psychiatry 154(3):355-362. https://doi. org/10.1176/ajp.154.3.355

46. Fisher HL, McGuffin P, Boydell J, Fearon P, Craig TK, Dazzan $P$ et al (2014) Interplay between childhood physical abuse and familial risk in the onset of psychotic disorders. Schizophr Bull 40(6):1443-1451. https://doi.org/10.1093/schbul/sbt201

47. Wigman JT, van Winkel R, Ormel J, Verhulst FC, van Os J, Vollebergh WA (2012) Early trauma and familial risk in the development of the extended psychosis phenotype in adolescence. Acta Psychiatr Scand 126(4):266-273. https://doi.org/10.111 1/j.1600-0447.2012.01857.x

48. Gottesman II, Shields J (1967) A polygenic theory of schizophrenia. Proc Natl Acad Sci U S A 58(1):199-205

49. International Schizophrenia Consortium, Purcell SM, Wray NR, Stone JL, Visscher PM, O'Donovan MC et al. (2009) Common polygenic variation contributes to risk of schizophrenia and bipolar disorder. Nature 460 (7256):748-752. doi:10.1038/nature08185

50. Chae S, Sim M, Lim M, Na J, Kim D (2015) Multivariate analysis of relationship between childhood trauma and psychotic symptoms in patients with schizophrenia. Psychiatry Investig 12(3):397-401. https://doi.org/10.4306/pi.2015.12.3.397

51. van Dam DS, Korver-Nieberg N, Velthorst E, Meijer CJ, de Haan L, For Genetic R et al (2014) Childhood maltreatment, adult attachment and psychotic symptomatology: a study in patients, siblings and controls. Soc Psychiatry Psychiatr Epidemiol 49(11):1759-1767. https://doi.org/10.1007/s00127-014-0894-0

52. Read J, Perry BD, Moskowitz A, Connolly J (2001) The contribution of early traumatic events to schizophrenia in some patients: a traumagenic neurodevelopmental model. Psychiatry 64(4):319-345

53. Limosin F (2014) Neurodevelopmental and environmental hypotheses of negative symptoms of schizophrenia. BMC Psychiatry 14:88. https://doi.org/10.1186/1471-244X-14-88
54. McGlashan TH, Hoffman RE (2000) Schizophrenia as a disorder of developmentally reduced synaptic connectivity. Arch Gen Psychiatry 57(7):637-648

55. Fosse R, Joseph J, Richardson K (2015) A critical assessment of the equal-environment assumption of the twin method for schizophrenia. Front Psychiatry 6:62. https://doi.org/10.3389/fpsyt .2015 .00062

56. Plomin R, DeFries JC, Loehlin JC (1977) Genotype-environment interaction and correlation in the analysis of human behavior. Psychol Bull 84(2):309-322

57. van Winkel R, Kuepper R (2014) Epidemiological, neurobiologi$\mathrm{cal}$, and genetic clues to the mechanisms linking cannabis use to risk for nonaffective psychosis. Annu Rev Clin Psychol 10:767791. https://doi.org/10.1146/annurev-clinpsy-032813-153631

58. Lecei A, Decoster J, De Hert M, Derom C, Jacobs N, MenneLothmann C et al. (2018) Evidence that the association of childhood trauma with psychosis and related psychopathology is not explained by gene-environment correlation: a monozygotic twin differences approach. Schizophr Res. doi:10.1016/j. schres.2018.05.025

59. van der Steen Y, Myin-Germeys I, van Nierop M, Ten Have M, de Graaf R, van Dorsselaer S et al. (2018) 'False-positive' selfreported psychotic experiences in the general population: an investigation of outcome, predictive factors and clinical relevance. Epidemiol Psychiatr Sci:1-12. doi:10.1017/S2045796018000197

60. Guloksuz S, van Nierop M, Bak M, de Graaf R, Ten Have M, van Dorsselaer $\mathrm{S}$ et al (2016) Exposure to environmental factors increases connectivity between symptom domains in the psychopathology network. BMC Psychiatry 16:223. https://doi. org/10.1186/s12888-016-0935-1

61. Guloksuz S, van Nierop M, Lieb R, van Winkel R, Wittchen HU, van Os J (2015) Evidence that the presence of psychosis in non-psychotic disorder is environment-dependent and mediated by severity of non-psychotic psychopathology. Psychol Med 45(11):2389-2401. https://doi.org/10.1017/S0033291715000380

62. Pries LK, Guloksuz S, Ten Have M, de Graaf R, van Dorsselaer S, Gunther N et al (2018) Evidence that environmental and familial risks for psychosis additively impact a multidimensional subthreshold psychosis syndrome. Schizophr Bull 44(4):710-719. https://doi.org/10.1093/schbul/sby051

63. Frissen A, Lieverse R, Drukker M, van Winkel R, Delespaul P, Group Investigators (2015) Childhood trauma and childhood urbanicity in relation to psychotic disorder. Soc Psychiatry Psychiatr Epidemiol 50(10):1481-1488. https://doi.org/10.1007/s0012 7-015-1049-7

64. Frissen A, Lieverse R, Marcelis M, Drukker M, Delespaul P, Group Investigators (2015) Psychotic disorder and educational achievement: a family-based analysis. Soc Psychiatry Psychiatr Epidemiol 50(10):1511-1518. https://doi.org/10.1007/s0012 7-015-1082-6

65. Croft J, Heron J, Teufel C, Cannon M, Wolke D, Thompson A et al. (2018) Association of trauma type, age of exposure, and frequency in childhood and adolescence with psychotic experiences in early adulthood. JAMA Psychiatry. doi:10.1001/ jamapsychiatry.2018.3155

66. Morgan C, Fisher H (2007) Environment and schizophrenia: environmental factors in schizophrenia: childhood trauma-a critical review. Schizophr Bull 33(1):3-10. https://doi.org/10.1093/schbu $1 / \mathrm{sb} 1053$

67. Newbury JB, Arseneault L, Moffitt TE, Caspi A, Danese A, Baldwin JR et al (2018) Measuring childhood maltreatment to predict early-adult psychopathology: comparison of prospective informant-reports and retrospective self-reports. J Psychiatr Res 96:57-64. https://doi.org/10.1016/j.jpsychires.2017.09.020

68. Fergusson DM, Horwood LJ, Boden JM (2011) Structural equation modeling of repeated retrospective reports of childhood 
maltreatment. Int J Methods Psychiatr Res 20(2):93-104. https:// doi.org/10.1002/mpr.337

69. Jacobs N, Rijsdijk F, Derom C, Danckaerts M, Thiery E, Derom R et al (2002) Child psychopathology and lower cognitive ability: a general population twin study of the causes of association. Mol Psychiatry 7(4):368-374. https://doi.org/10.1038/sj.mp.4000971
70. Verdoux H, van Os J (2002) Psychotic symptoms in non-clinical populations and the continuum of psychosis. Schizophr Res 54(1-2):59-65 